\title{
O ENSINO DE LÍNGUA INGLESA E OS SUJEITOS DA EJA: UM OLHAR SOBRE O LIVRO DIDÁTICO DE INGLÊS
}

\author{
English Language Teaching and YAE Students: \\ an Overview of the English Textbook
}

Agnaldo Pedro SANTOS FILHO

Universidade do Estado da Bahia agnpedro@gmail.com https://orcid.org/0000-0002-9695-2887

José Veiga VIÑAL JÚNIOR

Universidade do Estado da Bahia joseveigavinal@gmail.com https://orcid.org/0000-0001-5009-1551

Antônio AMORIM

Universidade do Estado da Bahia antonioamorim52@gmail.com https://orcid.org/0000-0003-3236-9139

RESUMO: Neste artigo, propomos fazer uma discussão sobre o livro didático de inglês para a Educação de Jovens e Adultos (EJA). Neste sentido, analisamos uma unidade didática de um livro de inglês para esta modalidade de ensino e questionamos se este recurso didático atende às necessidades e especificidades das pessoas da EJA, bem como a sua contribuição para uma aprendizagem crítica de inglês. A abordagem metodológica escolhida para esta investigação foi a qualitativa e os métodos de coleta de dados foram a pesquisa bibliográfica e documental. Concluímos que o desenvolvimento de material didático para a EJA precisa considerar as questões específicas que envolvem essa modalidade de ensino de forma a contribuir com uma aprendizagem significativa.

PALAVRAS-CHAVE: Educação de Jovens e Adultos; Ensino de Língua Inglesa; Livro Didático de Inglês.

ABSTRACT: This paper aims to discuss the English textbook for Youth and Adult Education (YAE). To do so, we analyzed an English textbook unit for this education segment; we question whether the English textbook fulfills the needs and specificities of YAE students, as well as, its contribution to a critical learning of English. The methodological approach chosen to develop this study was the qualitative and the datagathering methods were the bibliographical study and document 
research. We conclude from this study that the development of instructional material for YAE needs to consider the specific requirements of this education segment aiming at promoting a meaningful learning.

KEYWORDS: Youth and Adult Education; English Language Teaching; English Textbook.

\section{INTRODUÇÃO}

A Educação de Jovens e Adultos (EJA) tem se configurado como um espaço de inclusão social que visa a contribuir como desenvolvimento intelectual e humano dos sujeitos de direito que compõem essa modalidade de ensino, através de uma educação crítica, democrática, transformadora e de qualidade. Esses sujeitos de direito formam um grupo diverso com experiências, motivações e objetivos, sendo, portanto, dever de a escola oferecer uma formação de qualidade que atenda as especificidades desse público.

Neste contexto, o ensino de uma língua estrangeira tem um papel importante na formação integral desses indivíduos, porquanto o aprendizado e o uso de outro idioma oportunizam um contato com diferentes sociedades e culturas, expondo-os a outras realidades e levando-os à percepção das diferentes maneiras de se fazer algo, abrindo-lhes novos horizontes, aproximando pessoas e culturas. Sendo assim, é importante possibilitar a esses estudantes o intercâmbio de cultura e conhecimento, visando à transformação do indivíduo e do meio em que este vive.

O ensino de uma língua na escola não deve visar apenas objetivos instrumentais como o estudo de habilidades isoladas ou exercícios de vocabulário e gramática descontextualizados, mas a aprendizagem e o uso da língua dentro de um contexto real de comunicação. Para que isso ocorra, o professor deve considerar a realidade onde esses aprendizes estão inseridos de modo que o uso da língua faça sentido. O sujeito da EJA, ao vir para a sala de aula, traz consigo os conhecimentos que foram construídos através de suas experiências dentro e fora do ambiente escolar e esse conhecimento deve ser valorizado e utilizado durante as aulas.

Para tanto, faz-se necessário que as aulas de língua inglesa na EJA disponham de recursos que contribuam com este processo de forma significativa, a fim de possibilitar ao educando uma relação entre a aprendizagem, o uso linguístico e o contexto social. 
Atualmente o recurso didático mais utilizado pelos professores no ambiente escolar é o livro didático, que, a depender de seu uso, pode ser um importante material de apoio a aprendizagem tanto para o professor quanto para o estudante, e muitas vezes é o único recurso disponível em algumas escolas públicas brasileiras.

Apesar dos avanços técnico-metodológicos e das pesquisas na área de ensino de línguas estrangeiras, as publicações de livros didáticos desse componente curricular para a EJA ainda são escassas e as disponíveis precisam adequar-se para atender as necessidades dos estudantes da EJA, pois não levam em consideração as especificidades dessa modalidade de ensino na sua pesquisa e produção. Quando há oferta de livros didáticos para esta modalidade, os mesmos são apenas uma adaptação ou reprodução dos livros didáticos para o ensino regular e a metodologia utilizada, os textos selecionados e os temas escolhidos para as unidades didáticas não são adequados ou atraentes aos sujeitos da EJA.

Os padrões sociais, culturais e econômicos apresentados pelo livro de língua estrangeira não têm relação com o contexto sociocultural e econômico dos estudantes das escolas públicas brasileiras, principalmente dos sujeitos da EJA. É comum encontrar no livro didático de inglês, unidades pedagógicas com modelos de sociedade que não se relacionam com as vivências dos jovens e adultos da EJA, nem com a sociedade em que estão inseridos, excluindo temas que podem ser considerados polêmicos, mas que fazem parte da vida cotidiana dos educandos, conforme discutido por Siqueira (2012) ao trazer a definição dessa prática como a "plastificação do livro didático de LE”. Essa é a prática que idealiza uma realidade distante dos sujeitos envolvidos no processo de ensino e aprendizagem.

É consenso que o livro didático tem um papel importante no ensino de língua estrangeira, contudo há pontos negativos e positivos que precisam ser considerados na sua utilização. O livro didático por si só não resolve as questões relacionadas ao ensino de línguas, mas esse recurso pode contribuir de forma positiva com o desenvolvimento linguístico dos aprendizes de língua estrangeira. Assim, é imperativo que o desenvolvimento de material didático para o aprendizado de línguas reflita sobre as questões que concernem ao aprendiz, a fim de propiciar uma formação adequada. Neste sentido é que trazemos como problemática questionar se o livro didático de inglês para a 
EJA atende as especificidades desta modalidade, trazendo à tona a representatividade desses sujeitos neste material.

Para consolidar esta investigação acerca do livro didático para a EJA e procurar respostas para o problema colocado acima, elegemos como objetivo geral investigar se as atividades propostas pelo livro de linguagens e códigos da Coleção Viver, Aprender atendem às especificidades da EJA. Diante deste contexto, traçamos como objetivos específicos verificar se as atividades propostas pelo livro em questão possibilitam uma aprendizagem comunicativa de língua inglesa por parte dos sujeitos da EJA e debater a representatividade desses sujeitos no livro didático em pauta.

Este estudo está organizado da seguinte forma: uma introdução, onde destacamos a temática, a delimitação do problema e os objetivos. Em seguida, apresentamos também os procedimentos metodológicos, a abordagem de pesquisa e o corpus. Além disso, trazemos a fundamentação teórica do estudo discutindo o perfil atual dos sujeitos, o ensino de línguas para EJA e o livro didático de inglês para esta modalidade selecionado para a pesquisa e a conclusão. Por fim, trazemos as referências utilizadas no estudo.

\section{PROCEDIMENTO DE PESQUISA}

Para a realização deste estudo optamos pela abordagem qualitativa que tem conquistado um maior espaço entre os pesquisadores por atender às demandas das mudanças sociais, estabelecendo, conforme pontua Chizzotti (2017), uma relação dinâmica entre o mundo real e o sujeito numa relação interdependente com o objeto e um vínculo entre o mundo objetivo e a subjetividade do sujeito, portanto oferece as condições para se compreender o contexto estudado. Corroborando essa ideia, Minayo (2010) explica que a pesquisa qualitativa responde a questões particulares que não podem ser quantificadas, dentro de um universo de significados cujos processos e fenômenos não podem ser reduzidos à operacionalização de variáveis.

Como método de investigação,para possibilitar as discussões acerca da temática do livro didático de inglês para EJA, utilizamos a pesquisa documental. Para Lüdke e André (2012, p. 38), a pesquisa documental é uma “[...] a análise documental que pode se constituir numa técnica valiosa de abordagem de dados qualitativos, além de complementar as informações obtidas por outras técnicas de coleta". Além da pesquisa 
documental, fizemos um levantamento bibliográfico de autores que discutem a Educação de Jovens e Adultos e o ensino de línguas de estrangeiras.

Nossos procedimentos de análises estão divididos em duas partes. No primeiro momento, fizemos um levantamento bibliográfico de pesquisadores que discutem as questões concernentes a pesquisa, com o objetivo de obter uma base teórica para o desenvolvimento da temática escolhida para o estudo. No segundo momento, iniciamos a análise das unidades didáticas dedicadas ao estudo de língua estrangeira - inglês do livro didático Coleção Viver, Aprender - Linguagens e Códigos da Editora Global, distribuído pelo Programa Nacional do Livro Didático para os anos de 2014, 2015 e 2016.

Nessa análise, examinamos, à luz das discussões trazidas pela literatura da área de educação e ensino de línguas estrangeiras, se as atividades e os textos propostos nas unidades didáticas do material em questão promovem a aprendizagem comunicativa de inglês como língua estrangeira e se levam em consideração as especificidades dos sujeitos da EJA na seleção e elaboração desses recursos de aprendizagem, trazendo à tona a sua representatividade.

\section{O PERFIL DOS SUJEITOS DA EDUCAÇÃO DE JOVENS E ADULTOS}

Na visão de alguns autores como Amorim, Pereira e Santos (2018, p. 127) a EJA é uma modalidade de ensino caracterizada pela diversidade dos sujeitos que a compõe, "sujeitos excluídos e reincluídos que tem vozes que contam suas histórias, falam de suas lutas e sonhos, motivam o campo da educação a almejar mais e rever conceitos". O que reafirma a EJA como uma proposta de inclusão desses sujeitos (DANTAS, 2019), assim, esses estudantes, adultos trabalhadores, chefes de família e idosos, pertencentes aos mesmos "coletivos sociais e culturais" (ARROYO, 2005, p. 33), ao (re)ingressarem na escola e nos espaços de aprendizagem encontram na EJA um espaço de crescimento, formação, socialização e inclusão social.

Nos últimos anos, o número de jovens matriculados na EJA tem aumentado expressivamente (AMORIM; PEREIRA; SANTOS, 2018), esse processo de "juvenilização" reconfigurou o perfil dos estudantes da EJA que antes era composta por pessoas maduras ou idosas, da zona rural, que nunca tinham frequentado a escola e passou a acolher jovens de origem urbana, conforme destacam Haddad e Di Pierro (2000). 
Sujeitos que interromperam seus estudos para entrar no mercado de trabalho prematuramente ou foram marcados por sucessivos casos de insucesso na sua trajetória educacional, evadindo-se ou sendo expulsos da escola (DANTAS, 2012), já que foram impedidos de entrar ou permanecer nela por conta de sua situação socioeconômica ou pela falta de políticas públicas eficazes que garantissem o seu acesso e permanência nos ambientes formais de aprendizagem.

Para se traçar o perfil atual dos estudantes da EJA no Brasil de forma mais detalhada, podemos observar os dados levantados pela Pesquisa Nacional por Amostra de Domicílios (PNAD) realizada no ano de 2018, que demonstram o perfil diverso dos estudantes da EJA no país.

Figura 1: Perfil dos estudantes da EJA de acordo com a PNAD 2018

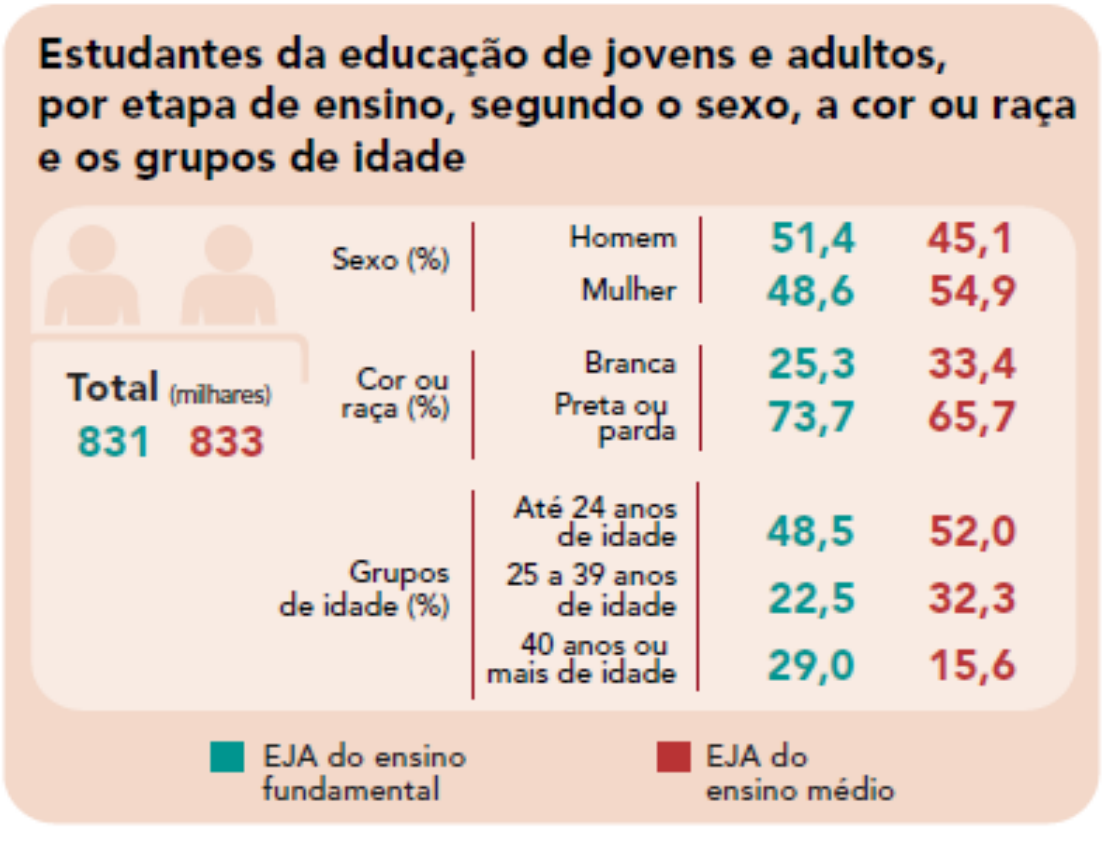

Fonte: IBGE (2018, p. 8).

A partir dos dados da PNAD 2018, confirma-se a crescente presença de um público mais jovem na EJA. No ensino fundamental, cerca de $49 \%$ dos educandos tem até 24 anos de idade e no Ensino Médio esse número chega a 52\%. O número de estudantes pretos e pardos também representa um número expressivo nessa modalidade de ensino, evidenciando, conforme destacado por Passos (2012, p.138), "as desigualdades acumuladas na experiência social da população negra nos processos de escolarização", 
levando esses sujeitos a procurar a EJA para concluir a sua educação básica.

Apesar do número de mulheres acima dos quarenta anos no Ensino Médio ainda ser tímido, reflexo de uma sociedade patriarcal dominada pelas relações de gênero, a presença feminina tem aumentado significativamente nessa modalidade, ultrapassando o número de homens em alguns níveis. Essa representação feminina na EJA é fruto das lutas sociais pela igualdade racial, social e de gênero. Tais dados mostram que a EJA, conforme pontuado por Laffin e Vigano (2016), se configura como espaço de empoderamento, aprendizagem e mudanças de grupos que foram marginalizados por conta da situação social, sexo, posição política e cultura.

Conhecer o perfil dos jovens e adultos da EJA no Brasil é imprescindível para o desenvolvimento de políticas públicas educacionais e metodologias de ensino que tenham como objetivo principal oportunizar um ensino emancipador, reflexivo e de qualidade. Neste sentido, Soares, Paiva e Barcelos (2014) destacam que

[...] oferecer educação de qualidade a sujeitos jovens e adultos, implica conhecer a realidade em que vivem esses sujeitos, reconhecer necessidades, possibilidades e aspirações, incluindo-as em processos educativos e reconhecidas como fundantes das experiências humanas no estar no mundo. (SOARES; PAIVA; BARCELOS, 2014, p. 29).

Considerar a realidade desses sujeitos possibilita ao professor uma reflexão sobre a sua prática, de modo que a aprendizagem seja significativa para o educando. Para tanto, os conteúdos apresentados não podem ser "retalhos da realidade, desconectados da totalidade" (FREIRE, 2018, p. 79-80). Os adultos possuem características cognitivas diferentes, influenciadas pela sua experiência, que "é o mais rico recurso para a aprendizagem do adulto" (KNOWLES, 1998, p. 40), pois possibilita a relação entre diferentes aprendizagens através da comparação e abstração e a construção de novos conhecimentos. Tais conhecimentos devem ser respeitados e discutidos no ensino dos conteúdos propostos (FREIRE, 2015), contribuindo com a construção de sentidos e com a formação de sujeitos ativos no seu processo de aprendizagem. 


\title{
O ENSINO DE INGLÊS NO CONTEXTO DA EDUCAÇÃO DE JOVENS E ADULTOS
}

Há muito é consenso que a aprendizagem de língua inglesa tem um importante papel social na formação do sujeito, pois amplia as possibilidades de acesso ao conhecimento científico e tecnológico, às novas culturas e à novos processos de construções identitárias. Além disso, a comunicação é necessária para o exercício da cidadania, já que é por meio dela que assimilamos e interpretamos informações, o que nos capacita a argumentar (VIÑAL JÚNIOR, 2017). Assim, o desenvolvimento dessas habilidades, a partir de uma concepção de língua como discurso, possibilita a construção de um espaço onde os sujeitos podem se perceber como "integrantes da sociedade e participantes ativos do mundo" (PARANÁ, 2008, p. 57). Dentro dessa ótica, Couto e Silva (2015) aduzem que:

\begin{abstract}
A aprendizagem de uma língua estrangeira pode levar o aluno ao autoconhecimento, a maior autonomia e discernimento sobre si e sobre o outro, pois a língua molda e reflete a identidade e a cultura. Com isto, percebe-se que o aprendizado de uma língua estrangeira, não é essencialmente a assimilação de conteúdos linguísticos, mas é também a absorção ou o acréscimo de uma nova cultura e identidade (COUTO; SILVA, 2015, p. 29).
\end{abstract}

Em vista disso, sendo a EJA um espaço de múltiplas aprendizagens, é imperativo que o ensino de língua inglesa nessa modalidade propicie uma aprendizagem linguística e cultural, bem como a formação de novas identidades, visando à formação integral do sujeito. Mediante o exposto, o ensino de língua estrangeira tem um papel importante na formação dos jovens e adultos da EJA, pois contribui para a construção da cidadania e favorece a participação social desses sujeitos, permitindo a compreensão e reflexão do mundo em que vivem, sendo capazes de interferir nele (BRASIL, 2002).

Complementando essa ideia, Viñal Júnior (2017) salienta que o ensino e a aprendizagem de uma língua promovem a prática social através da possibilidade de compreensão e expressão de sentimentos, valores e informações, dando a esses sujeitos ferramentas para o exercício da cidadania e para a sua constituição como cidadão político e social. Assim, aprender uma língua estrangeira "é perceber-se capaz de participar ativamente das práticas sociais (e, portanto, históricas, políticas, ideológicas e culturais) de 
construção de sentidos transitando entre linguagens e seus procedimentos de meaningmaking" (JORDÃO, 2013, p. 82), auxiliando na promoção de processos de emancipação.

Ao refletir sobre o ensino e aprendizagem de língua inglesa para aprendizes jovens e adultos, Cozma (2015) coaduna com as ideias de Paulo Freire (2015) quanto à valorização dos saberes que os educandos trazem da vida para a escola. Na visão da autora, esses sujeitos:

[...] trazem para a aula de inglês uma multiplicidade de experiências relacionadas não apenas à aprendizagem, mas também da vida em geral. Os professores podem se valer dessas experiências expandindo-as sempre que possível para conectá-las ao novo aprendizado. (COZMA, 2015, p. 1213, tradução nossa).

Para propiciar um aprendizado significativo de uma língua estrangeira na escola, as aulas devem utilizar recursos autênticos que reflitam o mundo real dos aprendizes. Trazer este mundo real para as aulas de inglês leva o estudante da EJA a participar ativamente no seu processo de construção do conhecimento e na aprendizagem de forma mais significativa, uma vez que a "[...] formação cultural dos estudantes adultos de inglês tem um importante papel na aprendizagem" (DUBOVIČIENĖ; GULBINSKIENĖ, 2014, p.141, tradução nossa) da língua, uma vez que o mesmo está inserido como protagonista do processo de construção do conhecimento.

Tendo em vista essas especificidades, Siqueira (2012) chama atenção para a necessidade de uma mudança na estrutura dos materiais didáticos para o ensino de inglês com o objetivo de atender às necessidades específicas dos aprendizes, fundamentadas por conteúdos culturais globais e da cultura do aluno, assim como pela inclusão de temas que fazem parte da sua realidade. Por conseguinte, o ensino de língua inglesa não pode partir da ótica neocolonialista descontextualizado da sociedade, negando o "seu papel crucial de refletir o mundo, já que, inegavelmente, como espaço sociopolítico privilegiado, a sala de aula não apenas reflete o mundo, ela é o mundo" (SIQUEIRA, 2012, p. 319).

Outro detalhe importante relativo à organização do livro didático de inglês para a EJA é a representatividade dos seus sujeitos nesse material, que é bem ressaltada por Camargo e Ferreira (2013) quando afirmam que: 
Os materiais didáticos são um exemplo da divisão étnica e do racismo velado na escola, muitos livros têm uma postura preconceituosa, machista, classista - em especial os materiais de Inglês, esses são marcados pela ideologia do branqueamento, a qual sobrepõe os brancos em relação aos negros. (CAMARGO; FERREIRA, 2013, p. 180).

Tais pressupostos levam à reflexão da necessidade de se representar a identidade diversa do aluno no livro didático de inglês como língua estrangeira de forma que possa refletir um ambiente escolar autêntico. Considerando-se que os estudantes da EJA no Brasil são, em sua maioria, negros, pardos e mulheres de classes populares, o livro didático precisa representar esses sujeitos de forma que não reforce estereótipos negativos, que conferem a eles posições de menor destaque como ocorre comumente não só no livro didático, mas também em outros espaços onde as "minorias" são representadas por moldes pré-definidos pela sociedade.

Outro ponto a se considerar na pesquisa e produção de materiais didáticos para o ensino de língua inglesa é a integração das quatro habilidades linguísticas: compreender, falar, ler e escrever (listening, speaking, writing e reading), na elaboração e escolha das atividades. Esse é um ponto relevante, já que se observa a carência de atividades comunicativas e a predominância do ensino de estruturas e vocabulário de maneira descontextualizada, distante da realidade.

Considerando a língua como um "espaço de construção de sentidos e representações de sujeitos e do mundo" (JORDÃO, 2013, p. 73), o ensino de língua inglesa deve oportunizar a construção de conhecimentos e a negociação de sentidos a partir da interação e do contexto social do educando. Esse objetivo pode ser alcançado através de atividades comunicativas que envolvam os aprendizes na compreensão, manipulação, produção e interação na língua alvo (NUNAN, 2010).

Estes tipos de atividades apoiam o processo de ensino e aprendizagem de língua estrangeira pois seu foco é centrado no aprendiz, não no professor que, neste contexto, assume um papel de mediador na construção do conhecimento. Esse modelo centrado no aluno é um aspecto importante no de línguas, pois as experiências de aprendizagem dentro da sala de aula são relacionadas às experiências desses alunos fora dela (NUNAN, 2015). Assim, o ensino parte do que os alunos já sabem de modo a engajá-los ativamente na sua própria aprendizagem e partir para a construção de novos conhecimentos, uma vez que os 
mesmos sentem-se mais envolvidos e estimulados quando podem utilizar seus conhecimentos e experiências pessoais em sala de aula.

A partir da análise dos estudos apresentados, constata-se que exercícios de tradução, repetição, memorização de vocabulário e estruturas isoladas não promovem a comunicação; assim, o aprendizado de língua estrangeira perde o sentido, já que não estimula os aprendizes a utilizar a língua de forma autêntica. Há que se considerar, portanto, que o ensino de língua inglesa para estudantes da EJA deve estar pautado em temas e atividades que envolvam situações do dia a dia dos aprendizes, que despertem seu interesse e que propiciem a troca de ideias, uma vez que essa aprendizagem precisa ter um objetivo e fazer sentido para os mesmos.

\section{APRESENTAÇÃo E ANÁLISE DO LIVRO DIDÁTICO DE INGLÊS PARA EJA}

Conforme mencionado anteriormente, o nosso objeto de análise é uma unidade didática do livro Coleção Viver, Aprender - Linguagens e Códigos, Educação de Jovens e Adultos da Editora Global. O livro, que faz parte do Programa Nacional do livro Didático, é composto por um compêndio de três disciplinas: língua portuguesa, língua estrangeira inglês e espanhol e artes, sendo organizado em três partes denominadas etapas, divididas em capítulos separados por disciplinas. A unidade escolhida para análise foi o primeiro capítulo da etapa 2, intitulado Text or test?

As unidades de inglês do livro em questão seguem uma estrutura que separa seus capítulos em seções que indicam o gênero textual ou o tipo de conteúdo a ser trabalhado. O capítulo escolhido para este estudo segue a mesma estrutura de separação por seções, a saber: Para Refletir I, Ler Receita, Ler Texto Informativo, Ler Biografia, Ler Provérbios, Para Refletir II, Ler Tabela e Produzir Texto, que serão analisadas a seguir.

A primeira seção do capítulo, denominada Para refletir, inicia-se com uma atividade de $w a r m-u p^{1}$, a partir da leitura de uma tirinha na língua materna, seguida de um parágrafo sobre a importância e as motivações se aprender uma língua estrangeira. Após a primeira atividade, os alunos são direcionados a uma atividade de pré-leitura em grupo onde os mesmos devem elencar os motivos que levam as pessoas a aprender inglês, após a

\footnotetext{
${ }^{1}$ Atividades de aquecimento utilizadas para a contextualização e o envolvimento do aluno na tarefa ou tópico a ser trabalhado em sala de aula.
} 
atividade introdutória são convidados a ler o texto intitulado "A importância de ler em inglês". Na terceira parte, os autores fazem uma explicação teórica sobre os modelos de processamento de leitura, bottom up e top down ${ }^{2}$.

Figura 2: Atividade de leitura.
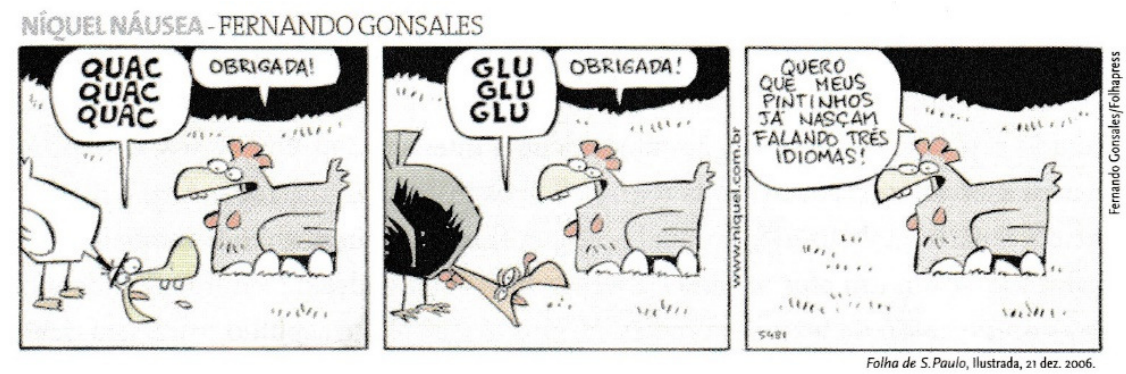

Q

uem de nós não tem o desejo de falar vários idiomas em um passe de mágica? Mas realidade é bem outra. Tudo aquilo que sabemos envolveu um aprendizado que implicou mais ou menos esforço, dependendo do conteúdo e das particularidades de cada indivíduo. Entre as particularidades, o interesse que nos despertam certos temas contribui muito para o êxito no processo de assimilação de um novo conhecimento. Quando falamos em interesse, estamos nos referindo não apenas à simpatia ou não pelo assunto que iremos aprender. Devemos considerar os motivos mais amplos pelos quais queremos aprender algo novo. Vamos refletir um pouco sobre os porquês de aprender inglês?

Fonte: Almeida (2013, p. 307).

Discutir a importância e as motivações para aprender uma língua estrangeira é importante para traçar objetivos didáticos e para conhecer os objetivos e motivações dos aprendizes, contudo discussões teóricas sobre leitura não têm sentido para estudantes neste contexto de aprendizagem, uma vez que o objetivo do ensino de língua inglesa na escola é o aprendizado da língua, não o aprendizado de teorias sobre a língua, uma vez que a "língua é uma ferramenta de comunicação, ao invés de um conjunto de regras" (NUNAN, 2015, p.13). Os alunos devem ser levados a utilizar estratégias de leitura no desenvolvimento das atividades em sala de aula, mas o conhecimento teórico sobre as mesmas é necessário para que o professor planeje as aulas e selecione os textos a serem trabalhados em sala de aula.

Em seguida o livro propõe a leitura do texto French Omelet, que se trata de uma receita dividida em cinco passos, a resolução de um exercício de compreensão geral do

\footnotetext{
${ }^{2}$ Modelos ascendentes (do texto para o leitor) e descentes (do leitor para o texto) de processamento da leitura.
} 
texto e de compreensão específica. O primeiro exercício direciona os alunos a uma atividade de pré-leitura e tem por objetivo ativar o conhecimento prévio do leitor que,segundo Kleiman (2013), é o conhecimento sobre o assunto que lhe permite fazer inferências para relacionar as partes do texto de forma coerente, sendo essencial para a compreensão do texto. A atividade traz tópicos para que os alunos observem alguns elementos do texto como um aquecimento para a leitura.

Excerto de exercício de compreensão leitora:

1. Observe os elementos não verbais. Trata-se de uma sequência de figuras que instrui o leitor quanto à preparação de uma receita. Os detalhes são fornecidos pelos elementos verbais.

2. Leia o título do texto. A palavra omelete, que já foi incorporada ao dicionário de língua portuguesa como omelete, denomina uma refeição de preparo fácil que faz parte dos hábitos culinários de muitos brasileiros. Descubra, pelo título, qual é a origem desse prato.

3. O formato do texto é universal. A ordem dos itens de uma receita culinária parece ser (sic) mesma em qualquer lugar do mundo, pois está associada aos procedimentos práticos da culinária.

4. O item introdutório fornece dados sobre o número de pessoas que essa receita pode servir e a quantidade precisa dos ingredientes necessários.

5. Os itens de I a referem-se aos procedimentos que devem ser seguidos na preparação de uma omelete.

6. Em notes, outra palavra cuja correspondente em português é similar — notas -, o editor fornece algumas informações adicionais que podem ser úteis.

(ALMEIDA, 2013, p. 309).

O segundo exercício é uma atividade de scanning $^{3}$ para que os alunos localizem palavras específicas no texto e copiem em uma tabela. Esse tipo de questão, "tipo cópia", sugere a transcrição de palavras ou frases de maneira mecânica (MARCUSCHI, 2011), não exigindo a interpretação para a resolução da tarefa. Esse exercício é importante para a compreensão leitora, contudo não pode ser o único tipo de exploração do texto, por não envolver o uso de outras habilidades, uma vez que compreender um texto não é apenas decodificar, "[...] é muito mais uma forma de inserção no mundo e um modo de agir sobre o mundo na relação com o outro dentro de uma cultura e uma sociedade" (MARCUSCHI, 2011, p. 89).

Conforme pode ser observado na atividade retirada do livro:

\footnotetext{
${ }^{3}$ Estratégia de leitura que consiste na localização de informações específicas de um texto.
} 
Observe o texto e preencha os campos:

- $\mathrm{N}^{\mathrm{o}}$ de pessoas servidas

- $\mathrm{N}^{\mathrm{o}}$ de ovos

- Temperos

- $\mathrm{N}^{\mathrm{o}}$ de colheres de água (fria ou quente?)

- Quantidade de manteiga

- Apetrechos necessários

(ALMEIDA, 2013, p. 309).

Conforme podemos observar nos dois exemplos das atividades com o texto French Omelet, as tarefas utilizadas para a compreensão textual já trazem as informações solicitadas de forma explícita e exigem dos alunos apenas a busca de informações no texto, não exigindo nenhum tipo de reflexão por parte do leitor. Esse tipo de atividade resume-se ao que Kleiman define como uma "manipulação mecanicista" sem a preocupação com o entendimento do significado do texto. O sentido do texto é construído a partir da interação de diferentes níveis de conhecimento, "o leitor utiliza na leitura o que ele já sabe, o conhecimento adquirido ao longo de sua vida" (KLEIMAN, 2013, p. 13), em conjunto com o conhecimento linguístico, textual e sociocultural.

Após os dois exercícios com o texto French Omelet, o livro traz a explanação do uso do imperativo e a definição de classes de palavras, mas em nenhum momento os alunos utilizamos tópicos gramaticais apresentados na seção, sendo um estudo baseado meramente em definições de classes de palavras. Apesar de importante para o uso de uma língua, o estudo de gramática de forma isolada não promove a aprendizagem, "a organização sentencial deve ser aprendida na interação com os aspectos semânticos e pragmáticos" (OLIVEIRA; CARNEIRO; AZEVEDO, 2016, p. 444). 
Figura 3: Fragmento de explanação gramatical

3. Adjectives - Usamos adjetivos para atribuir qualidade ou descrever pessoas e coisas. Os adjetivos em inglês não variam sua forma, não importa que se refiram a palavras no singular ou plural, masculino ou feminino, concretas ou abstratas, contáveis ou incontáveis. São usados antes dos substantivos. Por exemplo: cold water, cold omelets, cold pan. Em português, teríamos: água fria, mãos frias, almoço frio e dias frios.

4. Adverbs - Advérbios são palavras invariáveis que modificam verbos, adjetivos ou outros advérbios. Também podem modificar frases, expressando modos, lugares, qualidades ou causas. Em inglês, os advérbios de lugar respondem à pergunta Where?, como em Where are the eggs? Here!, e os advérbios de tempo respondem à pergunta When?, como em When are we going to eat the omelet? Now!. Os advérbios de lugar e tempo são posicionados no fim das sentenças. Os advérbios de fre quência respondem à pergunta How often?, como em How often do you eat omelets? I never eat omelets! I usually eat omelets two times a week. Normalmente os advérbios de frequência são usados antes dos verbos regulares e irregulares ou após o verbo to be, como em I always eat omelets e Peter is often late to supper. Os adjetivos em geral podem ser transformados em advérbios de modo acrescentando-se $\boldsymbol{l} \boldsymbol{\gamma}$ à sua terminação, como em slowly, happily, terribly e carefully.

5. Prepositions - Preposições são palavras invariáveis que podem definir lugar, tempo ou movimento. Por exemplo: Pour in eggs; Draw cooked egg from edge of pan inwards...

6. Conjunctions - Conjunções são palavras usadas para unir duas partes de uma sentença, conectando seus sentidos. Por exemplo: Shake omelet to edge of the pan and tip it over on to warm serving plate; Interesting, I like eggs but I don't like omelets.

Fonte: Almeida (2013, p. 311).

O exemplo exposto acima traz o ensino de estrutura gramatical com foco apenas na forma, não privilegiando a comunicação. Neste sentido, Nunan (2010) destaca que ensino de gramática pode ser complementado a partir de atividades relacionadas ao tópico da aula, que levem os aprendizes a utilizar as estruturas linguísticas de forma comunicativa dentro de um contexto, aperfeiçoando as suas habilidades de comunicação, uma vez que nesse tipo de abordagem a aprendizagem de gramática deve privilegiar o seu uso em contexto, em oposição ao método tradicional que considerava competência comunicativa o conhecimento sobre a gramática.

A atividade que segue é de compreensão oral nos mesmos padrões e utiliza as mesmas perguntas do exercício da atividade anterior. Além disso, a atividade pede para que os alunos comparem uma receita americana a uma francesa, mas em momento algum faz comparações com a receita brasileira ou discute o consumo desse prato no Brasil, referenciando apenas a cultura do outro sem considerar a cultura do próprio aluno. Assim, é importante que o professor atue como mediador na realização da tarefa com o objetivo de aproximar o conteúdo abordado no exercício ao contexto cultural dos educandos.

Extrato da atividade de compreensão oral:

Ouça a receita de American Omelet apresentada no CD de áudio desta coleção. Anote no quadro o que conseguir entender e converse com seus colegas sobre as diferenças entre a receita que você ouviu e a de French Omelet, lida no início da atividade ler receita. 
- $\mathrm{N}^{\mathrm{o}}$ de pessoas servidas

- $\mathrm{N}^{\mathrm{o}}$ de ovos

- Temperos

- $\mathrm{N}^{\mathrm{o}}$ de colheres de água (fria ou quente?)

- Quantidade de manteiga

- Apetrechos necessários

(ALMEIDA, 2013, p. 311).

O excerto da atividade retirada do livro mostra um exercício de compreensão do texto oral baseado apenas na decodificação, além disso não é feito um trabalho de 'aquecimento' (pre-listening) para que os alunos sejam engajados na atividade. Richards e Rodgers (2014) definem a compreensão oral como um processo de compreensão do discurso que envolve o conhecimento linguístico, o conhecimento prévio, o tópico e as expectativas do ouvinte. Sendo um processo interativo que engaja diversos níveis de compreensão, o ensino de compreensão oral deve promover essa interação para que o sentido seja construído.

A seção seguinte, Ler Texto Informativo, é iniciada a partir do trecho de um livro sobre a história da cachaça. A primeira tarefa solicita que os alunos façam uma leitura do texto para que encontrem palavras cognatas; após o exercício, explica-se porque essas palavras são de fácil compreensão para os falantes de português. Em seguida, os alunos são direcionados a uma atividade de vocabulário, onde devem construir um glossário a partir da tradução de algumas palavras do texto apresentado na seção:

Figura 4: Excerto de atividade

\begin{tabular}{|l|l|}
\hline \multicolumn{1}{|c|}{ Inglês } & Português \\
\hline talk(ing)* & \\
\hline (may) sound & \\
\hline forbid(den) & \\
\hline show(s) & \\
\hline label(ing)* & \\
\hline
\end{tabular}

Fonte: Almeida (2013, p. 312). 
No exemplo de atividade acima, observa-se o uso do texto apenas para o exercício de vocabulário a partir de perguntas metalinguísticas, que "levam o aluno a copiar vocábulos e depois identificar qual o significado que mais se adapta ao texto" (MARCUSCHI, 2011, p. 101). Após a conclusão dessa tarefa, o vocabulário utilizado não é explorado de forma contextualizada, limitando-se apenas a construção do glossário. É importante ressaltar que, como destaca Nunan (2010), o vocabulário estudado precisa ser utilizado e repetido através de diferentes tipos de abordagem durante o processo de aprendizagem a fim de que esse vocabulário seja consolidado e utilizado pelos alunos em outros contextos.

A próxima tarefa traz um texto intitulado The Sugar Factory, que fala da cana de açúcar no Brasil. O trabalho com o texto começa com uma contextualização e, como no primeiro texto, com uma explicação teórica sobre modelos de processamento de leitura, em seguida há uma prática de compreensão leitora a partir de perguntas abertas que exigem apenas que o leitor encontre as informações no texto e as transcreva em português, numa atividade de decodificação, já que "indagam sobre conteúdos objetivamente inscritos no texto", com respostas centradas somente no texto, conforme pontua Marcuschi (2011, p. 101). Para esta atividade não é feita uma relação com o conhecimento que os aprendizes já têm sobre o assunto discutido, esperando do aluno apenas a localização de informações.

Trecho de atividade de compreensão leitora:

1. Que posição a cana-de-açúcar ocupava no contexto socioeconômico brasileiro?

2. De onde se originou a cana-de-açúcar?

3. Quando e em que reinado a cana-de-açúcar começou a ser cultivada em Portugal, especificamente na ilha da madeira?

4. Qual a origem da palavra sugar?

(ALMEIDA, 2013, p. 314).

Nas seções Ler Biografia e Ler Provérbios, o mesmo padrão de tarefa do texto anterior é repetido e, novamente, há uma página dedicada a definições de conceitos e de tópicos gramaticais descontextualizados. Em seguida, na seção Para Refletir II, as autoras fazem uma discussão, a partir de um texto em português, sobre globalização. Na seção Ler Tabela, há um texto em português sobre tecnologias de comunicação e informação e uma 
tarefa a partir de uma pesquisa realizada com trabalhadores estadunidenses sobre produtividade:

Figura 5: Texto 'Tabela'

\begin{tabular}{|l|l|l|}
\hline & \multicolumn{1}{|c|}{2005} \\
\hline Work completed in an average day & $3 / 4$ & $2 / 3$ \\
\hline Average time spent on a computer at work (weekly) & $9.5 \mathrm{~h}$ & $16 \mathrm{~h}$ \\
\hline E-mails a day & - & 46 (nearly half unsolicited) \\
\hline Workers who feel very productive & $83 \%$ & $51 \%$ \\
\hline Workers who completed at least half the day planned work & $82 \%$ & $50 \%$ \\
\hline Workers who call themselves very successful & $40 \%$ & $28 \%$ \\
\hline
\end{tabular}

A discussão sobre os efeitos da globalização, que ativou seus conhecimentos prévios e a sua própria experiência para auxiliá-lo nesta atividade, acionou o processo top down de leitura.

A compreensão da tabela, na qual você trabalhou com os dados contidos no texto, acionou o processo bottom up de leitura.

Fonte: Almeida (2013, p. 319).

O tipo de leitura exigido para a atividade acima baseia-se apenas na comparação das mudanças ocorridas nos Estados Unidos, em nenhum momento os alunos são levados a fazer uma comparação ou uma discussão pensando o contexto no qual estão inseridos, não explorando as possibilidades de levar os alunos a refletirem sobre o seu papel na sociedade o mundo fora da sala de aula no desenvolvimento das atividades, conforme destaca Jordão (2006). É preciso aproximar o conteúdo trabalhado em sala da realidade do aluno, por isso Siqueira (2012) ressalta a importância da inserção de conteúdos culturais, principalmente da cultura nativa do aluno, pela inclusão de temas que fazem parte de sua realidade social. A tabela acima poderia trazer uma discussão sobre as mudanças que também ocorreram no Brasil, privilegiando a identidade e os contextos sociopolíticos e econômicos dos sujeitos inseridos no processo de ensino-aprendizagem.

Na última seção da unidade, há uma proposta de produção escrita em português sobre globalização e uma roda de leitura para a socialização dos textos. Em toda a unidade é observada a predominância do uso da língua materna nas atividades, não privilegiando a língua estudada para as produções. O exercício da produção escrita durante o aprendizado de línguas é importante independentemente do nível linguístico, pois oportuniza a 
aprendizagem, uma vez que, conforme endossa Nunan (2015, p. 77) "como a leitura, a escrita não é apenas uma ferramenta de comunicação, mas também um importante instrumento para o crescimento e o desenvolvimento intelectual".

\section{CONCLUSÃO}

O objetivo deste trabalho consistiu em analisar uma unidade de inglês do livro didático do PNLD Coleção Viver, Aprender - Linguagens e Códigos, Educação de Jovens e Adultos da editora Global. De modo mais específico, analisamos se as atividades e os textos propostos pelo material em questão promoviam uma aprendizagem comunicativa de inglês, levando em consideração o perfil dos sujeitos da EJA e as especificidades dessa modalidade de ensino. A partir da análise dos textos, das atividades de compreensão oral e escrita, da gramática e produção escrita, identificamos alguns problemas referentes a abordagem utilizada pelas autoras nas atividades do livro.

No que tange ao ensino de leitura, a unidade escolhida para o estudo traz textos de gêneros variados como tirinha, tabela, biografia, receita culinária, entre outros. Nessas atividades observamos a predominância de questões de interpretação de textos que não exigem do leitor nenhum tipo de interpretação do texto lido, resumem-se a identificação e cópia do conteúdo solicitado. Além disso, as atividades de pré-leitura não oportunizam a exploração do conhecimento prévio do aluno, uma vez que a contextualização traz tópicos com respostas óbvias, encontradas na própria pergunta.

Quanto ao ensino de estrutura gramatical, as unidades apresentam seções dedicadas à gramática que se constituem de pequenos textos com definições de tópicos gramaticais de forma descontextualizada do tópico do texto que estava sendo trabalhado. As estruturas apresentadas nessas seções não são exploradas em nenhum tipo de exercício, nem nas atividades propostas posteriormente, ou seja, o conteúdo estudado não é utilizado pelos alunos nem em atividades de estudo gramatical, nem em atividades comunicativas, ficando o conteúdo isolado do resto da unidade.

A respeito do desenvolvimento da compreensão e produção oral, há uma carência de atividades dedicadas a estas habilidades. Não há no material nenhum tipo de texto oral que promova o contato dos alunos com a língua falada para que os mesmos adquiram familiaridade com os sons da língua em estudo e o único exercício de compreensão oral 
proposto é uma reprodução da atividade feita com o texto escrito anteriormente. Para o desenvolvimento da produção oral, não há nenhuma atividade proposta em língua inglesa, os únicos exercícios em que há interação oral são em língua materna, não havendo comunicação na língua alvo.

O livro didático de inglês tem um importante papel na aprendizagem dos sujeitos da EJA, muitas vezes é a partir dele que estes têm o seu primeiro contato com a língua em um ambiente formal de aprendizagem. A sua pesquisa e produção devem adequar-se de forma criteriosa aos interesses e a realidade do aluno com atividades que desenvolvam uma competência intercultural comunicativa para que as aulas de inglês estimulem os estudantes ao aprendizado da língua e contribua com a formação integral dos sujeitos.

\section{REFERÊNCIAS}

ALMEIDA, N. A. et al. Coleção Viver, Aprender: Linguagens e Códigos, Ensino Médio. 1.ed. São Paulo: Global, 2013.

AMORIM, A.; PEREIRA, M.; SANTOS, J. Os Sujeitos Estudantes da EJA: um olhar para as diversidades. Revista Internacional de Educação de Jovens e Adultos, v.1, n.1, p.122135, 2018. Disponível em: <http:// repositorio.pucrs.br/dspace/handle/10923/14598>. Acesso em: 06 jun. 2019.

ARROYO, M. Educação de Jovens e Adultos: um campo de direitos e de responsabilidade pública. In: SOARES, L.; GIOVANETTI, M. A.; GOMES, N. L. Diálogos na educação de jovens e adultos. Belo Horizonte/MG, Autêntica, 2005, p.19-50.

BRASIL. Proposta Curricular para a Educação de Jovens e Adultos: segundo segmento do ensino fundamental. Língua Estrangeira. Brasília: Secretaria de Educação Fundamental, 2002.

CHIZZOTTI, A. Pesquisas em ciências humanas e sociais.12. ed. São Paulo: Cortez, 2017.

COUTO, L. R; SILVA, A. C. A Interculturalidade na Sala de Aula de Língua Inglesa: Uma Análise De Textos De Um Livro Didático. Clarabóia, Jacarezinho, n.2, v.2, p.23-41, 2015. Disponível: <http://seer.uenp.edu.br/index.php/claraboia/article/view/600/pdf_43>. Acesso em: 02 nov. 2019.

COZMA, M. The Challenge of Teaching English to Adult Learners in Today's World. Procedia - Social and Behavioral Sciences, Atenas, v.197, p.1209-1213, 2015. Disponível em: $\quad<$ https://www.sciencedirect.com/science/article/pii/S1877042815043815>. Acesso em: 25 out. 2019. 
DUBOVIČIENĖ, T.; GULBINSKIENĖ, D. Learning / Teaching EFL to Adult Learners at Language Courses. Man and the World, Vilnius, v.16, n.3, p.138-149, 2014. Disponível em: $<$ http://www.zmogusirzodis.leu.lt/index.php/zmogusirzodis/article/view/90/0 >. Acesso em: 05 nov. 2019.

DANTAS, T. R. A formação de professores em EJA: uma experiência pioneira na Bahia. Educação e Contemporaneidade. Salvador, v.21, n. 37, p.147-162, 2012.

DANTAS, T. R. A formação de professores em educação de jovens e adultos (EJA) na perspectiva da inclusão social. Revista de Educação, Ciência e Cultura. Canoas, v.24, n.1, p.29-39, 2019.2 Disponível em: $<$ https://revistas.unilasalle.edu.br/index.php/Educacao/issue/view/249>. Acesso em: 07 set. 2020.

FERREIRA, A. J.; CAMARGO, M. O racismo cordial no livro didático de língua inglesa aprovado pelo PNLD. Revista da Associação Brasileira de Pesquisadores/as Negros/as $(A B P N)$, v.6, n.12, p.177-202, 2014. Disponível em: $<$ http://abpnrevista.org.br/revista/index.php/revistaabpn1/article/view/182>. Acesso em: 24 nov. 2019.

FREIRE, P. Pedagogia do Oprimido. 65.ed. São Paulo: Paz e Terra, 2018.

FREIRE, P. Pedagogia da Autonomia. 51.ed. São Paulo: Paz e Terra, 2015.

HADDAD, S.; DI PIERRO, M. C. Escolarização de jovens e adultos. Revista Brasileira de Educação, Rio de Janeiro , n.14, p.108-130, 2000. Disponível em: $<$ http://www.scielo.br/scielo.php?script=sci_arttext\&pid=S141324782000000200007\&lng=en\&nrm=iso >. Acesso em: 20 set. 2018.

IBGE. Pesquisa Nacional por Amostragem de Domicílios (PNAD). Disponível em: $<$ https://biblioteca.ibge.gov.br/visualizacao/livros/liv101657_informativo.pdf $>$. Acesso em: 28 jun. 2018.

JORDÃO, C. M. O ensino de línguas estrangeiras: de código a discurso. In: VAZ BONI, V. Tendências Contemporâneas no Ensino de Línguas. União da Vitória: Kaygangue, $2006 . \quad$ Disponível em: $<$ https://www.academia.edu/1423122/O_Ensino_de_L\%C3\%ADnguas_Estrangeiras_de_c \%C3\%B3digo_a_discurso $>$. Acesso em: 20 set. 2020.

JORDÃO, C. M. Abordagem comunicativa, pedagogia crítica e letramento crítico farinhas do mesmo saco? In: ROCHA, C. H.; MACIEL, R. F. (Org.). Língua estrangeira e formação cidadã: por entre discursos e práticas. Campinas: Pontes Editores, 2013, p. 6990 .

KLEIMAN, A. B. Texto e leitor: aspectos cognitivos da leitura. 15.ed. Campinas: Pontes, 2013. 
KNOWLES, M. S. The adult learner: the definitive classic in adult education and human resource development. San Diego: Elsevier Butterworth-Heinemann, 1998.

LAFFIN, M. H. L. F.; VIGANO, S. M. M. A Educação de Jovens e Adultos como um espaço de empoderamento das mulheres. EJA em debate, n. 7, p.1-19, 2016. Disponível em: <https://periodicos.ifsc.edu.br/index.php/EJA/article/view/2105>. Acesso em: 12 jun. 2019.

LÜDKE, M.; ANDRÉ, M. E. D. A. Pesquisa em educação: abordagens qualitativas. 2.ed. São Paulo: EPU, 2012.

MARCUSCHI, L. A. Compreensão textual como trabalho criativo. Universidade Estadual Paulista. Prograd. Caderno de formação: formação de professores didática geral. São Paulo: Cultura Acadêmica, 2011, p.89-103, v.11. Disponível em: <http://acervodigital.unesp.br/handle/123456789/40358>. Acesso em: 28 jan. 2019.

MINAYO, M. C. S. (Org.) Pesquisa Social: teoria, método e criatividade. 29.ed. Petrópolis: Vozes, 2010.

NUNAN, D. Teaching English to Speakers of Other Languages: an Introduction. New York: Routledge, 2015.

NUNAN, D. What is task-based language teaching? In: Task-Based Language Teaching. Online publication. Cambridge: Cambridge University Press, 2010. Disponível em: $\quad<$ https://www.cambridge.org/core/books/taskbased-language-teaching/what-istaskbased-language-teaching/AC480B43A9144470E55BD2DB6D56FC9D $>$. Acesso em: 07 nov. 2019.

OLIVEIRA, A. L. A. M.; CARNEIRO, M. M.; AZEVEDO, A. M. T. Ensino de gramática baseado no uso: uma experiência de produção de materiais por professores. Revista brasileira de linguística aplicada. Belo Horizonte, v.16, n.3, p.441-459, 2016. Disponível em: $\quad<$ http://www.scielo.br/scielo.php?script=sci_arttext\&pid=S198463982016000300441\&lng=pt\&nrm=iso >. Acesso em: $04 \mathrm{dez} .2019$.

PASSOS, J. c. Mostrando as disparidades entre brancos e negros no acesso, permanência e conclusão dos percursos escolares. EJA em Debate, Florianópolis, v.1, n.1, p.137-158, 2012. Disponível em: <http://incubadora.periodicos.ifsc.edu.br/index.php/EJA $>$. Acesso em: 12 set. 2020.

PARANÁ. Secretaria de Estado da Educação. Diretrizes Curriculares da Educação Básica: língua estrangeira moderna. Curitiba, PR: SEED, 2008.

RICHARDS, J.; RODGERS, T. Approaches and methods in language teaching. Cambridge: Cambridge University Press, 2014.

SIQUEIRA, D. S. P. Se o inglês está no mundo, onde está o mundo nos materiais didáticos de inglês? In: SIQUEIRA, D. S. P.; SCHEYERL, D. (Orgs.) Materiais didáticos 
para o ensino de línguas na contemporaneidade: contestações e proposições. Salvador: EdUFBA, 2012.

SOARES, A. C. S.; PAIVA, J.; BARCELOS, L. B. Educação Continuada, Qualidade e Diversidade: um olhar complexo sobre aprendentes jovens e adultos. Debates em Educação, Maceió, v.6, n.11, p.17, 2014. Disponível em: $<$ http://www.seer.ufal.br/index.php/debateseducacao/article/view/1328 > . Acesso em: 24 out. 2019.

VIÑAL JUNIOR, J. V. O ensino da Língua Estrangeira como ferramenta para a emancipação das pessoas da Educação de Jovens e Adultos: potencialidades e reflexões. Revista Horizontes de Linguística Aplicada, v. 16, n. 1, 2017. Disponível em: $<$ https://periodicos.unb.br/index.php/horizontesla/article/view/7428 > . Acesso em: 10 set. 2020 .

Recebido em: 06 jul. 2020. Aceito em: 29 set. 2020. 